\title{
A Formula for the Measurement of Freedom
}

\section{Mehran Mazinani}

Mehran M. Marinani is a Ph.D. candidate at the University of Utah. He is currently finishing his dissertation titled "On Liberty in the First Iranian Constitution." His research interests include political history of Iran, comparative politics of the Middle East, and philosophy of social sciences, particularly hermeneutical methodologies.

\begin{abstract}
In this paper I shall explore how it is possible to measure freedom defined as whether or not a definite set of choices are actually available to a people, who have enough effective power to exercise them, regardless of whether they may or may not wish so. At first, two sets of data produced by two leading organizations-Freedom House and Human Development Programme-will be examined. Then, it will be suggested how it is feasible and advantageous to couple these two methods in order to set forth a more comprehensive formula. The primary objective of this paper is to present this formula.
\end{abstract}

Keywords: Human Development Programme; Human Rights; Freedom House; Freedom; the Middle East 


\section{Introduction}

There are two basic ways to define the concept of liberty: (i) liberty has two interrelated negative and positive concepts (Berlin's theory), or (ii) liberty is only one concept but has various conceptions (McCallum's theory). Since the publication of Isaiah Berlin's 'Two Concepts of Liberty,' liberty is more often than not split into two spheres: good versus bad, liberal versus totalitarian, negative versus positive, and freedom from versus freedom to (Berlin 1969). According to Berlin, the answer to 'what is the area within which the subject-a person or group of persons - is or should be left to do or be what he is able to do or be, without interference by other persons' demarcates the area of negative freedom from; and the answer to 'what, or who, is the source of control or interference that can determine someone to do, or be, this rather than that' designates the extent of one's positive freedom to (Berlin 1969, 121-2). This view has been extensively criticized, most brilliantly by McCallum, Feinberg, and Taylor (McCallum 1967; Feinberg 1973; Taylor 1979). McCallum proposes that freedom means freedom of something (the agent $=\mathrm{X}$ ) from something (constraint $=\mathrm{Y}$ ) to do or be something (objective $=\mathrm{Z}$ ). A true statement of freedom ought to contain all three elements: $\mathrm{X}$ is free from $\mathrm{Y}$ to do/be $\mathrm{Z}$ (McCallum 1967, 315). Although McCallum's formula has its own shortcomings, it has attracted many philosophers (Gray 1980; Gray 1991). If we agree that liberty is one concept (as against two negative versus positive), then it constitutes several conceptions, such as self-determination, self-mastery, absence of impediments, availability of choices, effective power, and status. All in all, what these scholars, notably Berlin and McCallum, try to accomplish is to explain the meaning of freedom.

Here freedom is defined as whether or not a definite set of choices are actually available to a people, who have enough effective power to exercise them, regardless of whether they may or may not wish so. Freedom, to put it most concisely, means to have options. Freedom of expression, for instance, is not the act of expressing my beliefs, thoughts, and feelings. I may remain silent. It rather means having the option of expressing myself. Freedoms are analogous to a set of doors that one can walk through whether or not one wishes to do so. Here I am concerned with the availability of the doors that could be walked through, regardless of whether one may or may not want to walk. Thus, freedom is understood as the availability of a set of options (i.e., doing $\mathrm{X}$, having $\mathrm{Y}$, and becoming $\mathrm{Z}$ ) to a people, who have enough effective power to exercise them, regardless of whether they may or may not wish so.

Having defined freedom, the main concern then becomes the measurement of freedom. We know what freedom is, but how can we measure it? In this regards, there are two main approaches: 
abstract approach, which is itself divided to philosophical speculation (Steiner 1983) and mathematical examination (Gabor and Gabor 1954), and empirical approach (Humana 1992). Here I concentrate on the empirical approach, particularly by focusing on two sets of data produced by Freedom House and Human Development Programme. After explaining how these two organizations measure freedoms, while using twenty two Middle Eastern countries as case studies, it will be suggested that it is possible and indeed advantageous to couple these two approaches in an attempt to put forth a more comprehensive formula which, if the argument is sound, deserves to be expanded and utilized as a better tool in the measurement of freedom.

\section{Freedom House}

On December 10, 1948, the UN adopted the Universal Declaration of Human Rights (UDHR). The UDHR's self-claimed objective is to put forth a set of 'a common standard of achievement for all peoples and all nations' (cf. article 2). ${ }^{2}$ Similar statements are declared in other manifestos, such as The International Covenant on Civil and Political Rights (articles 9 and 10), The International Covenant on Economics, Social, and Culture Rights, The American Convention on Human Rights (article 7), The African Charter on Human and Peoples' Rights (article 6), and The European Convention on Human Rights (article 5), and in its Protocol IV (article 1, 9, and 10) (Lawson1996, 969-70). The UDHR also proclaims that

Article 21: Everyone has the right to take part in the government of his country, directly or through freely chosen representatives. (2) Everyone has the right of equal access to public service in his country. (3) The will of the people shall be the basis of the authority of government; this will shall be expressed in periodic and genuine elections which shall be by universal and equal suffrage and shall be held by secret vote or by equivalent free voting procedures.

Article 21 is crucial in the measurement of freedom, when it is empirically employed as the underlying assumption by relevant organizations, particularly Freedom House (FH), which is 'the most used tool for measuring democracy'(Giannone2010, 69 and 75-6). FH declares that its methodology is driven from related portions of the UDHR. In line with the UDHR's article 21, the foundational assumption held in writing the FH's surveys is that freedom of all peoples is attainable most effectively in liberal democracy. Thus, 'a country cannot be an electoral

\footnotetext{
2 Throughout the paper every quote, concerning the Universal Declaration of Human Rights, such as its articles is found at the United Nation's official website (www.un.org) accessed March 20, 2012, unless otherwise stated.
} 
democracy if significant authority for national decisions resides in the hands of an unelected power, whether a monarch or a foreign international authority. ${ }^{33}$ The UDHR's $17^{\text {th }}$ article, as another example, is the basis for the FH's survey on freedom of press (i.e., opinion, expression, etc.). Similar to the UDHR, FH asserts that its focus is on individuals' freedoms, regardless of cultural differences across the globe. Lastly, FH asserts that it does not suffice to measure freedom as claimed in a given country's constitution, or institutional laws, and 'places a greater emphasis on whether these rights are implemented in practice.' That is, it calculates the actualized state of freedom as enjoyed by individuals.

FH measures freedom in accordance with two categories: political rights (i.e., electoral process, political pluralism and participation, and functioning of government), and civil liberties (i.e., freedom of expression and belief, associational and organizational rights, rule of law, and personal autonomy and individual rights). The political rights (PR) category consists of 10 questions and civil liberty (CL) includes 15 questions for each of which a country could gain a score between 0 to 4 . So, the maximum for PR is 40 (10 questions times 4$)$ and for PL is 60 (15 questions times 4), and the possible total number of summed scores is 100.The information based on which these questions are scored 'comes from the US State Department and Amnesty International country reports'(Landman, 2004,921-922). FH's website also displays an extensive list of other public sources, including publications, broadcasts, and organizations. Then, each PR and CL is averaged in order to determine an overall status, which could be Free, Partly Free, or Not Free (ranging from 1 to 7). According to FH,

i. A Free country [1.0 to 2.5] is one where there is open political competition, a climate of respect for civil liberties, significant independent civic life, and independent media.

ii. A Partly Free country [3.0 to 5.0] is one in which there is limited respect for political rights and civil liberties. Partly Free states frequently suffer from an environment of corruption, weak rule of law, ethnic and religious strife, and a political landscape in which a single party enjoys dominance despite a certain degree of pluralism.

iii. A Not Free country [5.5 to 7.0.] is one where basic political rights are absent, and basic civil liberties are widely and systematically denied.

Having a liberal democratic model in mind, the majority of the Middle Eastern countries are given a low level of freedom (2011), as demonstrated in Graph 1.

\footnotetext{
3 Throughout the paper every quote, concerning the Freedom House is found the Freedom House's official website (www.freedomhouse.org) accessed March 20, 2012, unless otherwise mentioned.
} 


\section{Graph 1: FH}

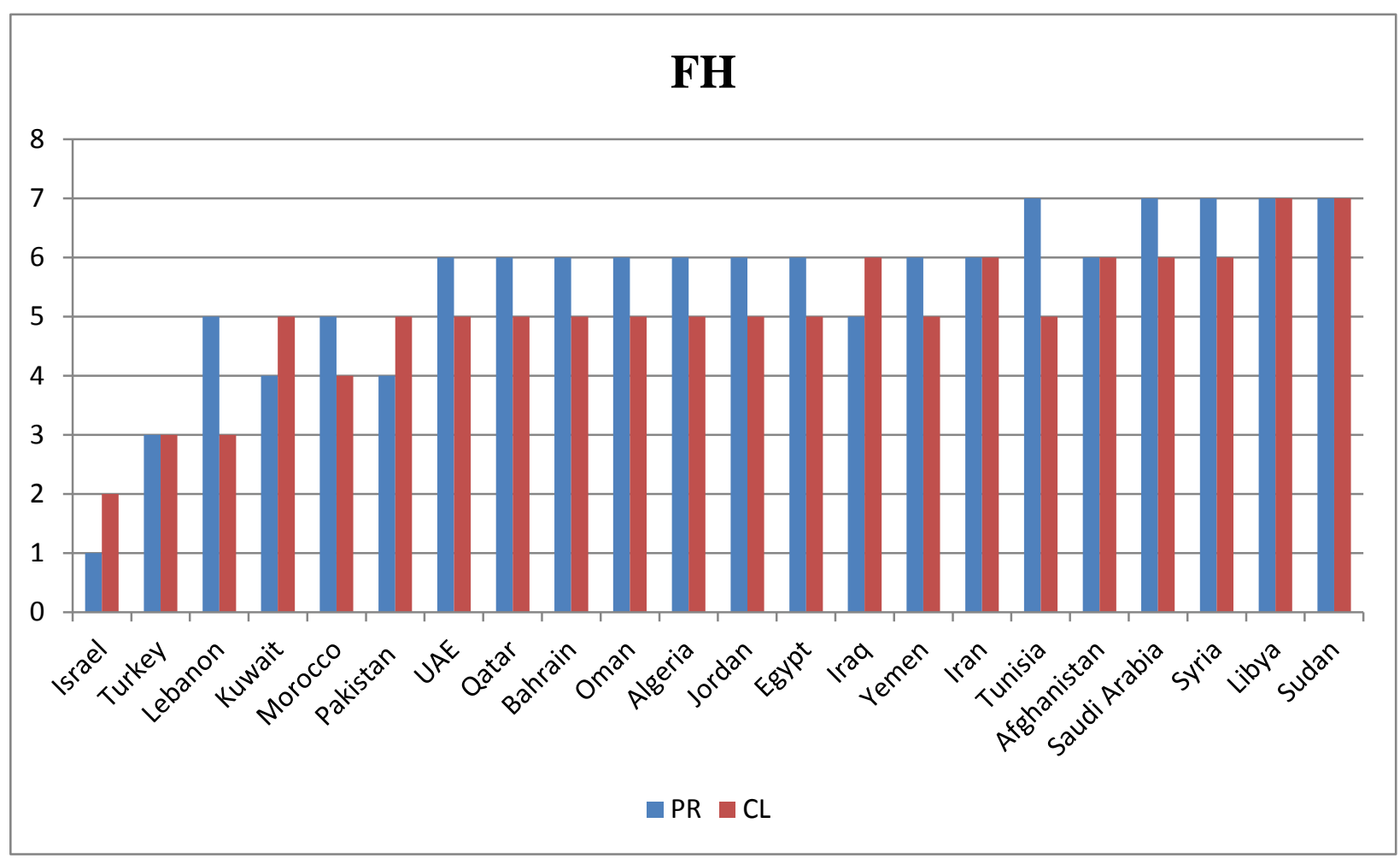

Several criticisms have been made against $\mathrm{FH}$, particularly its biases against communist and Islamic countries (Scoble and Wiseberg 1981; Bollen 1986; Bollen and Paxton 2000; Giannone 2010). Some have tried (yet failed) to put forth a mathematically objective formula (Gabor and Gabor 1954), and other accept the subjectivity in their measurement of freedom (Humana 1992). Despite all of the criticisms and suggestions, $\mathrm{FH}$ is still the most used source currently available - in the measurement of freedom as long as it is used to demonstrate the extent of freedoms accessible to a people (i.e., availability of options/freedom with no value-judgment) within certain civic and political spheres. This approach, nevertheless, can be improved by linking it to other aspects of freedom that has been covered by Human Development Programme.

\section{Human Development Programme}

There are things like health, education, affiliation, leisure, etc., without which life of a normal individual is damaged. These are called 'human core activities' by David Miller (2007, 127-32), 'welfare interests' by Joel Feinberg (1973, 32), and more commonly 'capabilities,' particularly developed by Amartya Sen. I shall focus on Sen's concept of capability, since it is better articulated and empirically applied by Human Development Programme in an attempt to represent his theory of freedom in light of his broader conceptual framework. 
According to Sen, functioning is what a person wants to do and be; or, what is conceived as valuable to do and be, such as being well-nourished, or participating in communal life. Functioning(s), therefore, plays a constitutive role in making one's being or identity. Capability is what a person can do and be, that is, the ability/opportunity to achieve what is conceived as valuable to do and be. Sen defines capability as 'the opportunity to achieve valuable combinations of human functioning - what a person is able to do or be' $(2005,153)$. Freedom consists of two aspects: opportunity and process. The opportunity aspect of freedom, similar to capability, indicates the ability of a person to gain what is aimed to be gained. The other aspect of freedom indicates the actual actions (i.e., process) of gaining the desired functioning(s). When, for instance, I am forced to be and/or do something when someone puts a gun to my head (i.e., interference), the process aspect of my freedom is violated; when I try to be and/or do something because there is no alternative choice, the substantive or opportunity aspect of my freedom is violated. The capability approach is helpful, if the opportunity aspect of freedom is under examination (Sen 2005, 153, also see the end note 3 on p. 164). 'The term freedom, in the form of capability, is used here to refer to the extent to which the person is free to choose particular levels of functioning (such as being well-nourished), and that is not the same thing as what the person actually decides to choose'(Sen 2005, 155). In a nutshell, Sen distinguishes between doing and being able to do.

Sen famously illustrates his theory by a simple example: a person who willingly practices fasting is different from a person who suffers from a famine, even though the outcome (starvation) is the same. Consider another example: in a desert I am allowed to go everywhere that I wish and drink everything that I like, but where I live (Slat Lake City), I must constantly stop at the stop lights. Yet, there is no reason to believe that I can actualize my freedoms in the desert, say, by going everywhere that I wish in the stifling heat, and drink water that I cannot find in reality, though I am theoretically allowed to do both. There are virtually countless things that I can do in Salt Lake (that I cannot do in the desert), such as drinking water at any time that I wish. I enjoy more things in Salt Lake because it provides me with more freedoms than the hypothetical desert in which freedom is unattainable.

Sen narrows his analysis to the most basic and necessary aspect of development, which is human development consisting of the state of health (long and healthy life), education (being knowledgeable), and income. ${ }^{4}$ These factors are not freedoms per se but they are helpful in

\footnotetext{
4 Throughout the paper every note, concerning Human Development Index is taken from its official website (http://hdr.undp.org/en/) accessed March 20, 2012, unless otherwise mentioned.
} 
gaining freedom. For example, a person with better education and health is more likely not only to earn more income, but also to drive more utilities from it, which means having more choices and less constraints (i.e., freedoms). The following table presents Human Development Indicators (HDI) under the Islamic Republic of Iran, as an example. It is then followed by the HDI's formulas applied to the case of Iran in an attempt to demonstrate the aggregation of the human development indicators:

Table1: Iran's HDI (1980-2011)

\begin{tabular}{|c|c|c|c|c|c|}
\hline Iran & $\begin{array}{c}\text { Life } \\
\text { expectancy at } \\
\text { birth }\end{array}$ & $\begin{array}{c}\text { Expected } \\
\text { years of } \\
\text { schooling }\end{array}$ & $\begin{array}{c}\text { Means years } \\
\text { of schooling }\end{array}$ & $\begin{array}{c}\text { GNI per } \\
\text { capita } \\
\text { (PPP\$) }\end{array}$ & $\begin{array}{c}\text { HDI } \\
\text { value }\end{array}$ \\
\hline 1980 & 51.1 & 8.4 & 2.1 & 7,113 & 0.437 \\
\hline 1985 & 50.1 & 8.4 & 2.8 & 7,119 & 0.454 \\
\hline 1990 & 61.8 & 9.3 & 3.7 & 6,248 & 0.534 \\
\hline 1995 & 68.2 & 10.9 & 4.4 & 6,791 & 0.596 \\
\hline 2000 & 69.8 & 12.2 & 5.1 & 7,678 & 0.636 \\
\hline 2005 & 71.3 & 12.2 & 6.1 & 9,140 & 0.671 \\
\hline 2011 & 72.7 & 12.7 & 7.3 & 10,339 & $\mathbf{0 . 7 0 7}$ \\
\hline
\end{tabular}

Dimension index $(x)=\frac{\text { Actualvalue }- \text { Minimumvalue }}{\text { Maximumvalue }- \text { Minimumvalue }}$

(The maximums and minimums are given by the HDI. ${ }^{5}$ )

Life expectancy index $(\mathrm{L})=\frac{72.7-20}{83.4-20}=0.831$

Mean years of schooling index $\left(e_{1}\right)=\frac{7.3-0}{13.1-0}=0.557$

Expected years of schooling index $\left(e_{2}\right)=\frac{12.7-0}{18-0}=0.705$

Education index $\left(\mathrm{E}=e_{1}+e_{2}\right)=\frac{\sqrt{(0.557) \cdot(0.705)}-0}{0.9778-0}=0.640$

Income index $(I)=\frac{\ln (10,339)-\ln (100)}{\ln (107,721)-\ln (100)}=0.664$

Human development Index $=\sqrt[3]{(\mathrm{L}) .(\mathrm{E}) \cdot(\mathrm{I})}=\sqrt[3]{(0.831) \cdot(0.640) \cdot(0.664)}=0.707$

\footnotetext{
5 The numbers for minimum and maximum, as well as the formula could be found at the Human

Development Index's official website (http://hdr.undp.org/en/), particularly see its section on 'Technical Note.'
} 


\section{Graph 2: HDI}

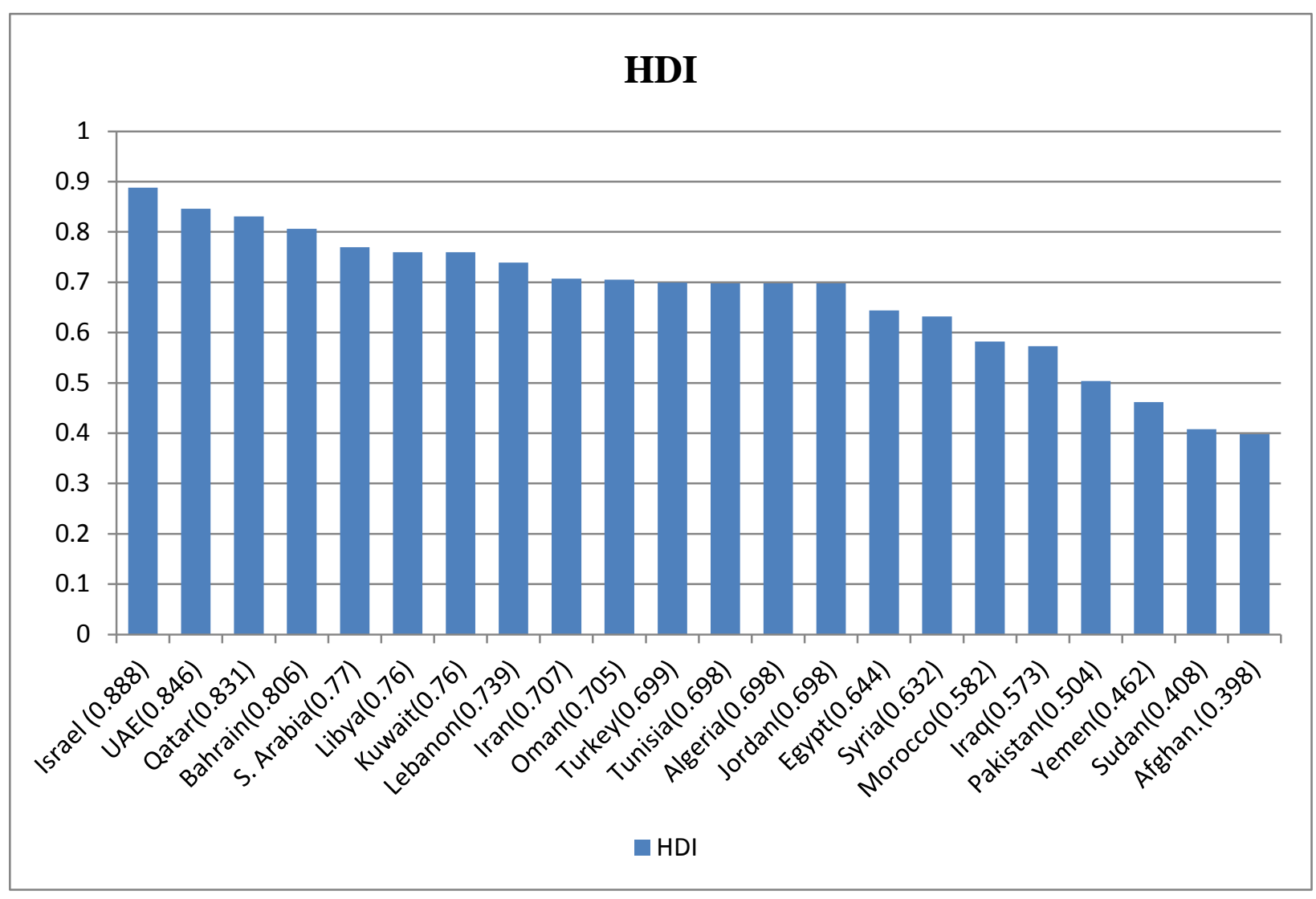

It must be noted that HDI is not a purely economic calculation. Human development defends that 'human beings are the real end of all activities [...] Income, commodities ('basic' or otherwise), and wealth do of course have instrumental importance but they do not constitute a direst measure of the living standard itself (Anand and Sen 1994, 1). Focusing on Gross National Income (GNI) as the primary source for evaluating the state of development, as it has been traditionally done by economists, conceals how the income is spent, for instance whether it is used to promote health and education, or equipment's for torture (Sen 1987). Although HDI does not provide 'a direct measure of rights protection per se,' Landman suggests, 'such measures can elucidate the degree to which governments support activities that have an impact on human rights. In addition, development indicators have been increasingly employed as proxy measures for the progressive realization of economic, social and cultural rights'(Landman 2004, 925). All in all, although, the HDI is an improvement, it self-admittedly does not include socio-political freedoms, such as political participation or freedom of expression and association in its calculation. The capability approach basically targets the opportunity aspect of non-political freedoms. 
Needless to say, there are differences between FH and HDI; for example, the UDHR, on which FH relies, is the continuation of the philosophy of contractualist liberal thinkers, such as Hobbes and Locke (Odello 2011, 110); whereas, the capacity approach is a non-contractualist theory (Chatterjee and Sieger 2011, 987-993; Sen 2005, 151, 155-6). Regardless, these two could complete each other because their unit of analysis is individuals, and not cultural groups. Moreover, they do not reject each other's fundamental assumptions (e.g., concerning the desirability of education, health, income, civic and political freedoms); rather, they target two different but related sets of factors. The difficulty is how to couple them in order to reach an enhanced measurement of freedom. This shall be done in the remaining section.

\section{Full Freedom}

The data from FH is organized such that 1 presents the highest and 7 the lowest possible grade of freedom in a given country. The spacing between 1 and 2 all the way to 7 is assumed to be linear and constant (i.e., $1-2=1 ; 2-3=1 ; 3-4=1$; etc.). In this manner, improving from 7 to 6 is as easy (or difficult) as improving from 3 to 2 , or 2 to 1 . FH approach is stationary in the sense that it calculates the state of freedom, rather than the necessary effort required to reach a 'status.' The following example attempts to plainly prove the logic behind my suggestion. In bicycling industry an average mountain bike cost approximately $\$ 500$. It is the lower end, though still standard. If someone wants to improve the brake system, it can be easily done (minimal cost). If someone wants to improve brakes, seat, tires, tubes, and other typical components, the total cost would go up perhaps to $\$ 700$. In practice, with some minimal effort, the quality has gone up significantly. At this point, everything that may be improved (cost effectively) is considered. Next, if one decides to improve the gear system and weight of the bike, specialized material and redesigning of the system will be required. But, doing so will increase the cost significantly, perhaps up to $\$ 3000$. If we are going to participate in the Tour of France, incredible amount of study, including aerodynamics, contact friction, human efficiency, comfort, etc. has to be performed to optimize the system (bicycle and the rider). Even though the technological improvement might seem insignificant to unprofessional riders, since simpler improvements have been already implemented, every little change and improvement will be extremely costly. The cost of the bicycle, say, may go up to $\$ 15,000$ to $\$ 20,000$. In sum, at the cutting edge of the technology, the cost of improvement increases drastically; that is, the slope of cost becomes higher. In other words, the degree of improvement is increasingly decreasing, although the cost increases. 
Following the same logic, it appears that the uniform spacing (i.e., 1 to 2, 2 to 3, etc.) presented in FH system may not be applicable in all cases. If it is desired to correct the slope (from a constant slope to a variable slope) the proper approach would be to collect data in a specific case (e.g. education improvement at a specific year); plot them and fit the data to a 'trend.' It may be logarithmic, exponential, polynomial of degree 'x,' or other forms of a trend. This approach is accurate and provides data about the variable slope between points. The drawback of the accurate system may be not having enough data due to cost, man power, or lack of collaboration of the country. It also may change every year.

The alternative approach may be to use the scale analysis, also called order of magnitude analysis (order of magnitude of one is from 1 to 9. Order of magnitude of 10 is from 10 to 99, etc.) The order of magnitude analysis provides the general shape of the changing slope or curve. This approach is utilized to convert the constant slope of FH system to a changing slope. By doing so, it will consider, in a general sense, the effort that would take to go from a lower 'grade' to a higher one. This trend may simply be reached by inversing FH grading system. This means that 7 becomes $1 / 7,6$ will be $1 / 6$, so on and so forth. In this manner, the effort of a given country in a given year to get to a higher grade is considered as shown in Graph 3 (in which the y axis represents the cost or effort, and the vertical axis represents the $1 / \mathrm{FH}$ grade.) In this figure, the slope of improving the system to go from 7 to 6 (on the horizontal axis) is much smaller than going from 2 to 1 . Note that the slope is defined as the vertical length dividend by the horizontal length. Since the horizontal length is divided uniformly and are equal, the slope simply may be referred to as the vertical length. (The longer/taller the vertical length, the higher the slope.) Next the data obtained from FH (2011) was compared to a several trends. The best trend obtained was the polynomial degree four as shown in the equation below.

$$
Y=0.003 x^{4}-0.059 x^{3}+0.4276 x^{2}-1.4022 x+2.0282
$$

Where $\mathrm{Y}$ is the grade of the system (including the 'effort') and $\mathrm{x}$ is $\mathrm{FH}$ grade. The result is presented in Graph 3 and 4. 


\section{Graph 3: FH Grading}

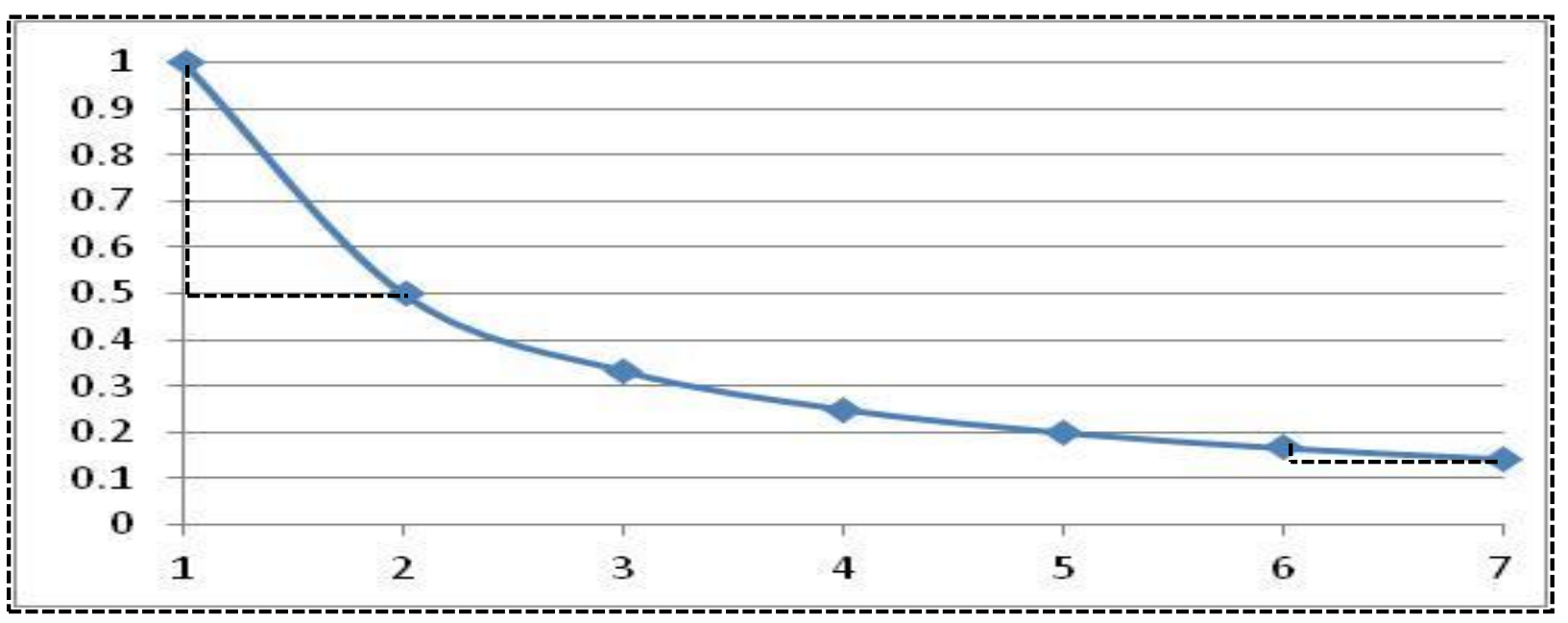

Now consider the FH trend juxtaposed to the polynomial degree 4 trend presented in Graph 4.

Graph 4: The FH Grade and the Polynomial Degree 4 Trend.

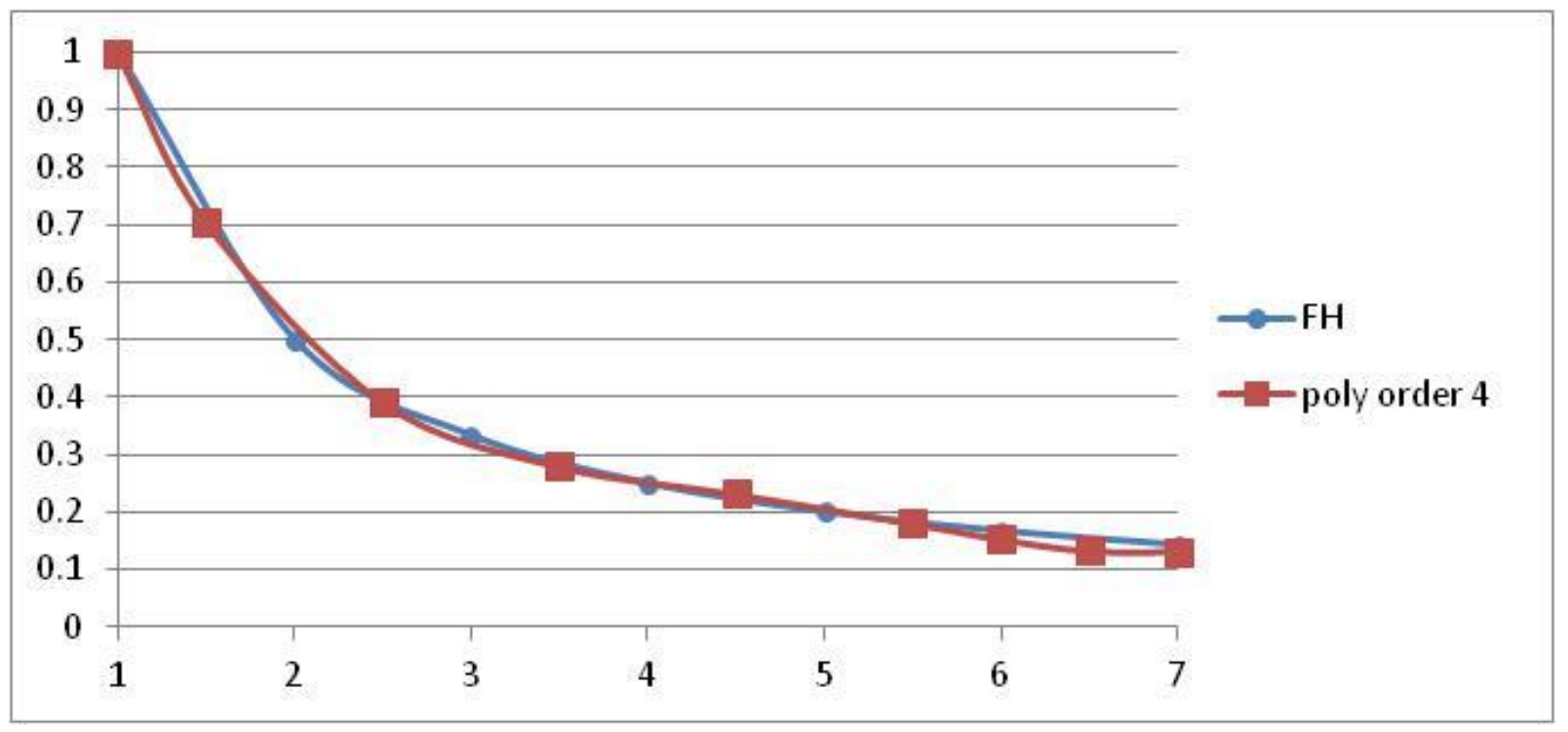

Regarding Graph 3, consider the areas of the two triangles at each end of the trend. The areas show the amount of effort needed for an improvement. Clearly, as it goes up from 7 to 1 the areas of triangles increase, and therefore the development becomes more costly and less easy to achieve. (Recall the example of the bicycle and how improvement takes more effort since the system is already saturated, that is, going from 7 to 6 takes less effort than going from 2 to 1 .)

Regarding Graph 4, the trends show that the polynomial degree 4 closely matches the FH slope, and may be used to evaluate the effort that takes to reach a fraction number (e.g. 3.5 or 5.75, etc.). Having said this, in order to lay out a simple mathematical correlation between FH's factors 
and those of HDI in an attempt to set forth a formula in which FH's and HDI's rankings are incorporated, FH and HDI should be scaled. That is, HDI's range is from 1 (maximum or best) to 0 (minimum or worst), whereas FH's results goes from 1 (maximum, or best) to 7 (minimum, or worst). By inversing 1 to 7 (i.e., $1, \frac{1}{2}, \frac{1}{3}, \frac{1}{4}, \frac{1}{5}, \frac{1}{6}, \frac{1}{7}$ ), as explained above, FH's results increase $\left(\frac{1}{7 \min } \rightarrow 1_{\max }\right)$ in the same fashion as HDI $\left(0{ }_{\min } \rightarrow 1_{\max }\right)$. Note that although HDI theoretically considers 0 to be its starting point, in practice, it never begins from 0 because when it is multiplied by the other factors, the final outcome will be 0 . This combination of FH and HDI, as presented in the following formula, depicts an incomprehensive picture of the state of freedom in a given country.

$$
\text { Full Freedom }(F F)=\sqrt[5]{\frac{L \cdot E \cdot I}{P R \cdot C L}}
$$

(PR . CL) is FH, and (L . E . I) is HDI's original formula. It is helpful to juxtapose the level of PR and CL, as measured by FH, the calculation of HDI, and results obtained according to the suggested formula (FF). Pay special attention to the ordering of the countries as presented in Graph 5 (compare the ordering with Graphs 1 and 2).

\section{Graph 5: FF}

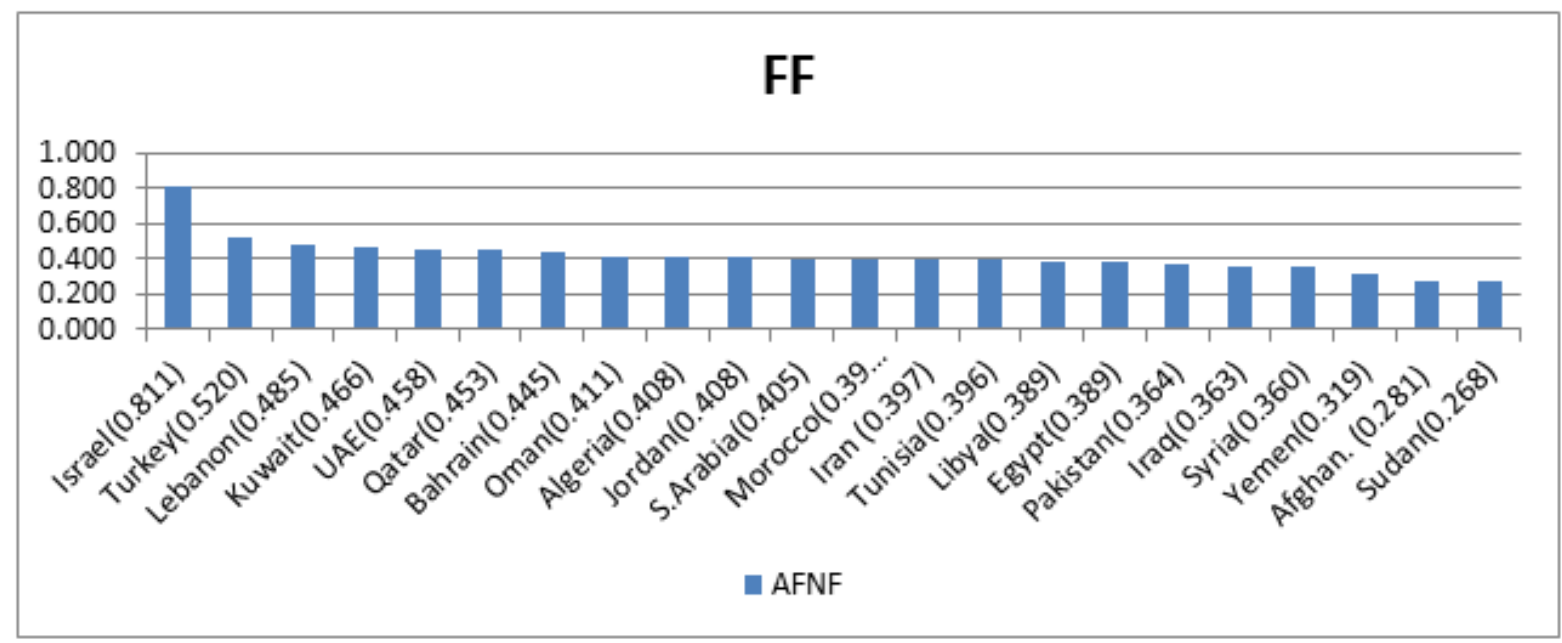

Evidently, the counties' ordering changes, as the criteria for the measurement vary.

i. $\quad \mathrm{FH}($ Graph 1): Turkey (no. 2) $>$ Pakistan (no. 6) $>\operatorname{Iran}$ (no. 16) $>$ Saudi Arabia (no. 19)

ii. $\operatorname{HDI}($ Graph 2): Saudi Arabia (no. 5)> $\operatorname{Iran}$ (no. 9) $>$ Turkey (no. 11) > Pakistan (no. 19)

iii. $\quad$ FF (Graph 5): Turkey (no. 2) $>$ Saudi Arabia (no. 11) $>\operatorname{Iran}$ (no. 13) $>$ Pakistan (no. 17) 
The key is not that the ordering just changes. It is obvious that it has to change, since more factors are taken into the calculation. The key is that the ordering is better modified and more sensible (e.g., unlike FH's calculation, Pakistan is not ranked highly any longer, and unlike HDI, Saudi Arabia does not occupy such a high place in comparison to other countries like Turkey.) It is absolutely critical to mark that the formula shows the magnitude of order, that is, countries rankings without being too much concerned with the precise number of any given country. In brief, the strengths of the new formula are its comprehensiveness (i.e., being sensible to standard of living as well as political and civic liberties), which increases its sensibility and simplicity. Being simple, however, should not be understood as being vulgar. In fact, even taking it as vulgar does not disvalue the formula as far as it is not falsified and replaced by a better formula. When Amartya Sen was asked by economist Haq to calculate and present the state of human development in given countries by a number, 'Sen says with a smile, 'I told him that this would be very vulgar." Haq replies, "Yes, I want a measure that is just as vulgar as GNP except it is better" (Sen 2004, 5). I hope FF advances the measurement of freedom, even if it is vulgar. 


\section{Bibliography}

Anand, Sudhir, and Amartya Sen. 1994. "Human Development Index: Methodology and Measurement." Human Development Report Office Occasional Paper. New York. Seen at http://hdr.undp.org/en/reports/global/hdr1994/papers/oc12.pdf (20 October 2012).

Berlin, Isaiah. 1969. Four Essays on Liberty. London: Oxford University Press.

Berlin, Isaiah, and Ramin Jahanbegloo. 1991. Conversation with Isaiah Berlin. NY: Charles Scribner's Sons.

Bollen, Kenneth A. 1986. "Political Rights and Political Liberties in Nations: an Evaluation of Human Rights Measures, 1950 to 1984.” Human Rights Quarterly 8 (4):567-91.

Bollen, Kenneth A., and Pamela Paxton. 2000. "Subjective Measures of Liberal Democracy." Comparative Political Studies 33 (1): 58-86.

Chatterjee, Deen, and Lynette E. Sieger. 2011. "Sen, Amartya." In Encyclopedia of Global Justice, edited by Deen Chatterjee, 987-993. New York: Springer.

Feinberg, Joel. 1973. Rights, Justice, and the Bunds of Liberty: Essays in Social Philosophy. NJ: Princeton University Press.

Gabor, D. and A. Gabor. 1954. “An Essay on the Mathematical Theory of Freedom,” Journal of the Royal Statistical Society, Series A, General, 117 (1): 31-72.

Giannone, Diego. 2010. "Political and Ideological Aspects in the Measurement of Democracy: the Freedom House case." Democratization 17 (1): 68-97.

Humana, Charles. 1992. World Human Rights Guide. New York: Oxford University Press.

Landman, Todd. 2004. "Measuring Human Rights: Principle, Practice, and Policy." Human Rights Quarterly 26 (26): 906-931.

Lawson, Edward. 1996. Encyclopedia of Human Rights. Washington, DC: Taylor and Francis.

McCallum, G. C. 1967. "Negative and Positive Freedom.” Philosophical Review 76(3): 312-334.

Miller, David. 2007. "National Responsibility and International Justice." In The Ethics of Assistance: Morality and the Distance Needy, edited by Deen Chatterjee, 123-147. Cambridge: Cambridge University Press.

Odello,Marco. 2011. "Indigenous Rights in the Constitutional State." In Emerging Areas of Human Rights in the 21st Century: The Role of the Universal Declaration of Human Rights, edited by Marco Odello and Sofia Cavandoli, 106-128. London: Routledge.

Sen, Amartya. 1987. "Food and Freedom." In AWorld to Make: Development in Perspective, edited by Francis X Sutton. NJ, 1990. 
Sen, Amartya. 2004. "Freedom as Progress." In Finance \& Development, interviewed by Laura Wallace, 4-7. Seen at http://www.imf.org/external/pubs/ft/fandd/2004/09/pdf/people.pdf (20 October 2012).

Sen, Amartya. 2005. "Human Rights and Capabilities." Journal of Human Development 6 (2):151166.

Scoble, Harry, and LaurieWiseberg. 1981. "Problems of Comparative Research in Human Rights." In Global Human Rights: Public Policies, Comparative Measures and NGO Strategies, ed. Ved Nanda, James Scarritt, and George Shepherd, 147-71. Boulder, C.O.:Westview.

Taylor, Charles. 1979. "What's Wrong with Negative liberty?” In The Idea of Freedom, edited by Alan Ryan, 175-93. Oxford: Oxford University Press. 